\title{
A Case of Fulminant Type 1 Diabetes in a Patient with Type 2 Diabetes Mellitus
}

\author{
Ji Min Kim, Ji Hye Han, Kyong Hye Joung, Ju Hee Lee, Hyun Jin Kim, Bon Jeong Ku* \\ Department of Internal Medicine, Chungnam National University Hospital, Chungnam National University School of Medicine, Daejeon, Korea
}

Fulminant type 1 diabetes mellitus is a recently identified subtype of type 1 diabetes characterized by abrupt disease onset, a very short ( $<1$ week) duration of diabetic symptoms, acidosis at diagnosis, negative status of islet-related autoantibodies, and virtually no C-peptide secretion. Cases of fulminant type 1 diabetes are prominently observed in East Asia, with several case reports and studies having originated from Japan. Indeed, a recent study from Japan reported that fulminant type 1 diabetes accounts for 15-20\% of type 1 diabetes cases associated with onset of ketosis or ketoacidosis. Since 2005, several fulminant type 1 diabetes cases have also been reported in South Korea; however, there have been no reports of cases in patients previously diagnosed with type 2 diabetes mellitus. Here, we report a rare case of fulminant type 1 diabetes in a patient previously diagnosed with type 2 diabetes.

Key words: Diabetes mellitus type 1, Diabetic ketoacidosis, Diabetes mellitus type 2

\author{
Received Junuary 21, 2016 \\ Reviewed March 3, 2016 \\ Accepted April 27, 2016 \\ *Corresponding author \\ Bon Jeong Ku \\ (iD) \\ http://orcid.org/0000-0002-3414-8949 \\ Department of Internal Medicine, \\ Chungnam National University School \\ of Medicine, 282 Munhwa-ro, Jung-gu, \\ Daejeon 35015, Korea \\ Tel: +82-42-280-7149 \\ Fax: +82-42-280-7995 \\ E-mail: bonjeong@cnu.ac.kr
}

\section{INTRODUCTION}

Type 1 diabetes mellitus is a disease in which destruction or damage of pancreatic $\beta$-cells results in marked hyperglycemia and ketosis, and is classified as either autoimmune (type $1 \mathrm{~A}$ ) or idiopathic (type 1B) diabetes. The destruction of $\beta$-cells in autoimmune type 1 diabetes occurs slowly, with onset of ketosis several years after initiation of $\beta$-cell damage. However, unlike the manifestation of autoimmune type 1 diabetes, some patients experience rapid destruction of $\beta$-cells, resulting in an abrupt onset of hyperglycemia and ketoacidosis. This condition is known as fulminant type 1 diabetes. In this type of diabetes, the duration of disease starting from a normal $\beta$-cell mass and normoglycemia to almost total destruction of $\beta$-cells and ketoacidosis is usually only a few days, and rarely exceeds 1 week. Thus, in patients with fulminant type 1 diabetes, symptoms occur within a week, but glycated he- moglobin (HbAlc) levels remain normal or near-normal. ${ }^{1}$

Since 2005, several fulminant type 1 diabetes cases have been reported in South Korea; however, there have been no reports of cases in patients previously diagnosed with type 2 diabetes mellitus. Here, we report a rare case of fulminant type 1 diabetes in a patient with type 2 diabetes.

\section{CASE REPORT}

A 51-year-old female presented to the Chungnam National University Hospital emergency room complaining of general weakness and hyperglycemia in January 2015. She had previously been diagnosed with type 2 diabetes at a local medical center in March 2014. At the time of diagnosis, her fasting plasma glucose was $140 \mathrm{mg} / \mathrm{dL}$ and her $\mathrm{HbAlc}$ was 7.0\%; C-peptide levels were not evaluated. The patient's blood glucose levels were well controlled with glimepiride 
(0.5-1 mg/day) and her HbAlc level had been 6.5\% four months prior to the current visit. Three days before admission, her blood glucose levels had gradually increased to over $400 \mathrm{mg} / \mathrm{dL}$, and her symptoms of polydipsia and general weakness worsened.

The patient was alert on admission, and her blood pressure was $100 / 60 \mathrm{mmHg}$, respiratory rate was 18 breaths per min, heart rate was 103 beats per min, and body temperature was $36.2^{\circ} \mathrm{C}$. The patient's height and weight were $155.4 \mathrm{~cm}$ and $60.5 \mathrm{~kg}$, respectively, her body mass index (BMI) was $25.05 \mathrm{~kg} / \mathrm{m}^{2}$, and she had not experienced any recent changes in weight. Arterial blood gas analysis (ABGA) showed a metabolic acidosis with an increased anion gap of $19.5 \mathrm{mEq} / \mathrm{L}$. Her plasma glucose levels were elevated to 431 $\mathrm{mg} / \mathrm{dL}$, and her serum osmolality, urea, and creatinine were also slightly elevated. Urine testing was positive for glucose $(3+)$ and ketones $(3+)$ (Table 1). Based on these findings, the patient was diagnosed with diabetic ketoacidosis (DKA). To rule out infection and cancer, chest X-rays and computed tomography (CT) of the abdomen were obtained, which showed no abnormal findings besides a moderately fatty liver.

Continuous insulin infusion with fluid replacement was initiated

Table 1. Initial and follow-up laboratory findings

\begin{tabular}{|c|c|c|c|}
\hline & & Day 1 & Day 2 \\
\hline \multirow[t]{4}{*}{$\mathrm{CBC}$} & White blood cells (per $\mu \mathrm{L}$ ) & 8,300 & 6,100 \\
\hline & Hemoglobin (g/dL) & 12.3 & 12.4 \\
\hline & Platelet (per $\mu \mathrm{L}$ ) & $201 \times 10^{3}$ & $230 \times 10^{3}$ \\
\hline & Segmented neutrophils (\%) & 81.10 & 46.3 \\
\hline \multirow[t]{6}{*}{ Chemistry } & Glucose (mg/dL) & 431 & 94 \\
\hline & Urea/Creatinine (mg/dL) & 25.0/1.09 & $9.0 / 0.54$ \\
\hline & $\mathrm{Na} / \mathrm{K} / \mathrm{Cl}(\mathrm{mEq} / \mathrm{L})$ & 132.1/4.6/100 & $136.8 / 4.28 / 102.9$ \\
\hline & Osmolarity (mOsmol/kg) & 309 & 290 \\
\hline & Amylase/Lipase (U/L) & $69 / 120$ & \\
\hline & C-reactive protein (mg/dL) & 4.1 & 2.1 \\
\hline \multirow[t]{5}{*}{ ABGA } & $\mathrm{pH}$ & 7.17 & 7.41 \\
\hline & $\mathrm{PaCO}_{2}(\mathrm{mmHg})$ & 22 & 32 \\
\hline & $\mathrm{PaO}_{2}(\mathrm{mmHg})$ & 109 & 88 \\
\hline & $\mathrm{HCO}_{3}-(\mathrm{mmol} / \mathrm{L})$ & 8.0 & 20.3 \\
\hline & $\mathrm{SaO}_{2}(\%)$ & 97 & 97 \\
\hline \multirow[t]{5}{*}{ Urinalysis } & SG & 1.018 & 1.009 \\
\hline & $\mathrm{pH}$ & 5.0 & 5.0 \\
\hline & Protein & $1+$ & - \\
\hline & Glucose & $3+$ & - \\
\hline & Ketone & $3+$ & - \\
\hline
\end{tabular}

CBC, complete blood count; $\mathrm{Na}$, sodium; $\mathrm{K}$, potassium; Cl, chloride; ABGA, arterial blood gas analysis; SG, specific gravity. to treat DKA. Glucose levels were measured hourly and the insulininfusion rate was varied from 2.5 to 10 units per hour to maintain adequate blood glucose levels (150-200 mg/dL). After 10 hours of treatment, the patient recovered from metabolic acidosis with a $\mathrm{pH}, \mathrm{pCO}_{2}$, and $\mathrm{HCO}_{3}{ }^{-}$of $7.40,30 \mathrm{mmHg}$, and $18.6 \mathrm{mmol} / \mathrm{L}$, respectively, as measured by ABGA, and her anion gap recovered to normal levels. After resolution of DKA, her general condition improved and she was able to start a diet treatment. At that time, her insulin therapy was changed to a basal bolus insulin regimen. Additional laboratory tests revealed that her $\mathrm{HbAlc}$ level was $7.0 \%$ and her fasting C-peptide level was very low $(0.01 \mathrm{pmol} / \mathrm{mL})$. Serum pancreatic lipase was elevated (two times above the upper limit of normal), but amylase was normal. Tests for glutamic acid decarboxylase antibody (GAD-Ab), islet cell antibody (ICA), and insulin autoantibody (IAA) were all negative. After her glucose levels stabilized with the basal bolus insulin regimen, the treatment was changed to premixed insulin. She was discharged on an insulin regimen consisting of 56 units of Novomix 30 FlexPen (70\% insulin aspart protamine suspension and 30\% insulin aspart) before breakfast and 20 units of Novomix 30 FlexPen before dinner. Three months after discharge, her HbAlc level had increased to $8.4 \%$ and her blood glucose levels were poorly controlled despite maintenance of the mixed split therapy. She achieved and maintained good glycemic control after her insulin regimen was changed to multiple injections. Six months later, we observed that the patient's C-peptide level remained low at $0.01 \mathrm{pmol} / \mathrm{mL}$, suggesting complete destruction of pancreatic $\beta$-cells.

\section{DISCUSSION}

Fulminant type 1 diabetes was first reported by Imagawa et al. in $2000 .^{2}$ The clinical characteristics of fulminant type 1 diabetes are as follows: 1) remarkably abrupt onset of disease; 2) very short ( $<1$ week) duration of diabetic symptoms including polyuria, polydipsia, and body weight loss; 3) acidosis at diagnosis; 4) negative status of islet-related autoantibodies such as ICA, GAD-Ab, IAA, or anti-IA-2; 5) virtually no C-peptide secretion ( < $10 \mu \mathrm{g} /$ day in urine); and 6) elevated serum levels of pancreatic enzymes.

Fulminant type 1 diabetes is observed particularly in East Asia, with several case reports and studies having originated from Japan. 
Indeed, a recent study from Japan reported that fulminant type 1 diabetes accounts for 15-20\% of type 1 diabetes cases associated with onset of ketosis or ketoacidosis. ${ }^{3}$ In another study from Korea, among 99 patients newly diagnosed with type 1 diabetes, seven patients (7.1\%) fulfilled the criteria for fulminant type 1 diabetes and among patients aged $\geq 18$ years at onset, $30.4 \%$ had fulminant type 1 diabetes. ${ }^{4}$

The prevalence of fulminant type 1 diabetes differs between Caucasians and East Asians. The first case in a Caucasian patient was reported in 2008, and only a few cases since then have been reported. ${ }^{5}$ The mean age of patients at onset of disease is $39.1 \pm 15.7$ years. Among 161 reported cases, only $8.7 \%$ have been under 20 years of age ${ }^{6}$, and there is no difference in prevalence with respect to gender. ${ }^{2,3}$ Fulminant type 1 diabetes is also a well-known cause of pregnancy-related DKA. ${ }^{6}$ In such cases, the onset is usually in the third trimester or immediately after delivery, and the prognosis for the fetus is extremely poor. ${ }^{3,7,8}$

The exact pathogenesis of fulminant type 1 diabetes is unknown. It has been suggested that certain genetic backgrounds pose an increased risk, including specific human leukocyte antigen (HLA) types. According to studies performed in Japan, fulminant type 1 diabetes occurs to a greater extent in HLA-DR4, whereas HLADR9 is more common in typical type 1 diabetes. In addition, haplotype analysis has revealed that DR4-DQ4 is significantly more frequent in fulminant type 1 diabetes. ${ }^{9,10}$ Viral infection is also suspected to play a role in the pathogenesis of this disease, with most patients exhibiting common cold-like and gastrointestinal symptoms prior to onset of disease. ${ }^{11,12}$ According to biopsies of the pancreas, severe reduction in the number of both $\beta$ - and $\alpha$-cells as well as lymphocytic infiltration of exocrine pancreatic tissue is often present. ${ }^{5,13}$ However, in our case, there was no evidence of infection based on the patient's history and physical examination. In addition to infection, a case of fulminant type 1 diabetes accompanying Reye's syndrome has been reported ${ }^{14}$, suggesting that anti-inflammatory drugs may destroy $\beta$-cells in some patients with fulminant type 1 diabetes. There have been no reports regarding other drugs that may cause fulminant type 1 diabetes. The only medication being taken by the patient in our case was glimepiride, and there is no known association of glimepiride and fulminant type 1 diabetes.

Autoimmune type 1 diabetes is associated with a reduced num- ber of $\beta$-cells, while fulminant type 1 diabetes is associated with a reduction in both $\beta$-cells and glucagon-producing $\alpha$-cells. ${ }^{3}$ As mentioned above, the most important difference between these two diseases is the extremely rapid transition from hyperglycemic symptoms to ketosis in fulminant type 1 diabetes. In addition, patients with fulminant type 1 diabetes need high-dose insulin therapy and have a higher BMI compared to autoimmune type 1 diabetes patients. In the present case, the patient's glucose levels were well controlled with one hypoglycemic agent. However, her glucose levels became rapidly elevated within 1 week of onset, at which time she developed DKA. In addition, more than 70 units of insulin and multiple insulin injections were eventually required to achieve glycemic control. Serum pancreatic enzyme levels are often elevated in fulminant type 1 diabetes, but fulminant type 1 diabetes is not necessarily accompanied by elevated serum pancreatic enzyme according to some case reports. ${ }^{5,15}$

DKA is a potentially life-threatening complication in patients with diabetes mellitus. DKA occurs predominantly in patients with type 1 diabetes, but it can occur in those with type 2 diabetes as well. A recent study that evaluated 138 consecutive admissions for moderate to severe DKA at a large academic center observed that $21.7 \%$ of cases of DKA involved patients with type 2 diabetes. In addition, nearly $70 \%$ of the admissions involved discontinuation of medication, and infections were present in approximately $50 \%$ of cases. ${ }^{16}$ Therefore, when DKA occurs in patients with type 2 diabetes, physicians should check for the presence of comorbid diseases. In the patient in our case, DKA occurred without interruption in medication or presence of comorbid disease. The patient also denied use of any medications or herbal supplements capable of altering blood glucose levels. Finally, the patient's history and laboratory tests were sufficient to diagnose fulminant type 1 diabetes according to the diagnostic criteria proposed by Imagawa et al. ${ }^{2}$ Therefore, fulminant type 1 diabetes mellitus should be included in the differential diagnosis of DKA occurring in a patient previously diagnosed with type 2 diabetes mellitus.

\section{CONFLICTS OF INTEREST}

The authors declare no conflict of interest. 


\section{REFERENCES}

1. Tanaka S, Endo T, Aida K, Shimura H, Yokomori N, Kaneshige $\mathrm{M}$, et al. Distinct diagnostic criteria of fulminant type 1 diabetes based on serum $\mathrm{C}$-peptide response and $\mathrm{HbA1c}$ levels at onset. Diabetes Care 2004;27:1936-41.

2. Imagawa A, Hanafusa T, Miyagawa J, Matsuzawa Y; Osaka IDDM Study Group. A novel subtype of type 1 diabetes mellitus characterized by a rapid onset and an absence of diabetesrelated antibodies. N Engl J Med 2000;342:301-7.

3. Hanafusa T, Imagawa A. Fulminant type 1 diabetes: a novel clinical entity requiring special attention by all medical practitioners. Nat Clin Pract Endocrinol Metab 2007;3:36-45.

4. Cho YM, Kim JT, Ko KS, Koo BK, Yang SW, Park MH, et al. Fulminant type 1 diabetes in Korea: high prevalence among patients with adult-onset type 1 diabetes. Diabetologia 2007; 50:2276-9.

5. Moreau C, Drui D, Arnault-Ouary G, Charbonnel B, Chaillous L, Cariou B. Fulminant type 1 diabetes in Caucasians: a report of three cases. Diabetes Metab 2008;34:529-32.

6. Shimizu I, Makino H, Osawa H, Kounoue E, Imagawa A, Hanafusa T, et al. Association of fulminant type 1 diabetes with pregnancy. Diabetes Res Clin Pract 2003;62:33-8.

7. Himuro H, Sugiyama T, Nishigori H, Saito M, Nagase S, Sugawara J, et al. A case of a woman with late-pregnancy-onset DKA who had normal glucose tolerance in the first trimester. Endocrinol Diabetes Metab Case Rep 2014;2014:130085.

8. Bresson L, Bourgain A, Depret T, Vambergue A, Dubos JP,
Deruelle P, et al. Ketoacidosis complicated by fetal death revealing fulminant diabetes during the third trimester of pregnancy. J Gynecol Obstet Biol Reprod (Paris) 2010;39:588-91.

9. Imagawa A, Hanafusa T, Uchigata Y, Kanatsuka A, Kawasaki E, Kobayashi T, et al. Different contribution of class II HLA in fulminant and typical autoimmune type 1 diabetes mellitus. Diabetologia 2005;48:294-300.

10. Kwak SH, Kim YJ, Chae J, Lee CH, Han B, Kim JI, et al. Association of HLA genotype and fulminant type 1 diabetes in Koreans. Genomics Inform 2015;13:126-31.

11. Imagawa A, Hanafusa T, Uchigata Y, Kanatsuka A, Kawasaki E, Kobayashi T, et al. Fulminant type 1 diabetes: a nationwide survey in Japan. Diabetes Care 2003;26:2345-52.

12. Inokuchi R, Matsumoto A, Odajima H, Shinohara K. Fulminant type 1 diabetes mellitus. BMJ Case Rep 2012;2012:bcr 2012006560.

13. Imagawa A, Hanafusa T. Fulminant type 1 diabetes-an important subtype in East Asia. Diabetes Metab Res Rev 2011;27: 959-64.

14. Imagawa A, Hanafusa T. Pathogenesis of fulminant type 1 diabetes. Rev Diabet Stud 2006;3:169-77.

15. Aoki K, Taniyama M, Nagayama C, Oikawa Y, Shimada A. T cell immunity to glutamic acid decarboxylase in fulminant type 1 diabetes without significant elevation of serum amylase. Ann N Y Acad Sci 2006;1079:181-5.

16. Newton CA, Raskin P. Diabetic ketoacidosis in type 1 and type 2 diabetes mellitus: clinical and biochemical differences. Arch Intern Med 2004;164:1925-31. 